\title{
Total Cost of Ownership for Supply Chain Management: A Case Study in an OEM of the Automotive Industry
}

\author{
Paulo Afonso \\ Production and Systems Department, University of Minho, Portugal \\ psafonso@dps. uminho.pt
}

\begin{abstract}
The selection of the best suppliers is a key issue for many companies. Nevertheless, it is important to highlight that the most economical supplier may not be the one that has the lowest purchase price. The cheapest supplier is the one that represents the lowest cost to the company, after being considered various aspects of supplying, such as quality, reliability of deliveries, the history of supplier performance, its location, its financial condition, etc. The goal of this paper is to discuss the application of the methodology Total Cost of Ownership (TCO) as a tool to support supplier's selection. The case studied allowed to understand TCO in practice, to study the contribution of the various cost parameters for the TCO and to demonstrate the procedures that support the systematic application of the TCO in a worldwide company.
\end{abstract}

Keywords: Supply Chain Management, Logistics Costs, Cost Management.

\section{Introduction}

Nowadays, the costs with materials, parts and components are a very high expense for companies in many worldwide supply chains. Thus, supplying strategies and supplier selection are particularly important.

However, the selection of a supplier should not be made on one unique criterion, usually the price of the goods purchased. Over the past few decades several methodologies have been developed in order to examine and compare the costs associated with each supplier allowing better decisions. Many managers realized that they real intend to select the best supplier, and the cheapest may not necessarily be what sells the cheaper product. Indeed, there are other significant costs beyond the price of the material or component such as: transportation costs, costs of non-quality and noncompliance, late deliveries, costs in after-sales service, etc. For all these reasons, companies need to establish close relationships with good suppliers.

A correct model to support the selection of suppliers includes in addition to the price a wide range of quantitative and qualitative elements (Ho et al., 2010, Humphreys et al., 2003). Furthermore, the excessive focus on the acquisition cost that prevailed for many years resulted in many hidden costs or costs that have been affecting the profits of these companies without managers realized it. The failure to consider environmental factors and risks, among other factors, also had important implications in various industries. 
In this context, the purchasing function plays a critical role in the competitiveness of modern firms and supply chains. Consequently, the business world and the academia have developed ways to improve the selection process of suppliers. Dickson (1966) reported 23 criteria for selecting vendors such as quality, reliability of deliveries, historical performance and its financial position. Weber et al. (2010), report various developments in this subject, as is the case of the selection methods of suppliers. Examples of such methods are reported by Aissaoui et al. (2007), Snijders et al. (2003), de Boer et al. (2001). Among others, several techniques can be used namely, the Analytic Hierarchical Process (AHP), the Analytic Network Process (ANP), Data Envelopment Analysis (DEA) and Case-based-reasoning (CBR). Still other authors, as is the case of Bevilacqua et al. (2006), Ferrin and Plank (2002), who address the selection criteria of suppliers. Typically, the main criterion for the selection of suppliers is the purchase price, i.e. the price at which the material or part is acquired. However, the literature has been also discussing the inclusion of other monetary and nonmonetary criteria such as risk level (Weber et al., 2010).

Among the existing cost-based methodologies it is important to emphasize the importance of methods that are applicable in the final stage of the decision process such as the Life-cycle costing (LCC), Zero-based pricing (ZBP), Cost-based supplier performance evaluation and also the Total Cost of Ownership (TCO). The life-cycle costing considers the purchase price and the costs the organization incurs to use, handle and maintain, and finally get rid of a particular material, part, equipment or product (Ellram, 1995). The zero-based pricing and the cost-based supplier performance evaluation are two methods used to consider the total costs incurred with each supplier. These methods give special attention to the costs of "doing business" with a particular supplier, including costs prior to the purchase moment (Ellram, 1995).

To evaluate the a $1^{\text {st }}$ Tier supplier in the automotive industry produces car radios and makes the assembly of electronic boards for various domestic and industrial applications. This company makes use of the TCO methodology for the selection of suppliers of plastic components, metal and electronic parts.

\section{Total Cost of Ownership}

Supplier selection strategies have been recognized as important by both the academia and the industry (Dogan and Aydin, 2011). Indeed, the high technical specialization of the firms and the consolidation of global supply chains in various industries have led to an increase of subcontracting costs, costs with subassemblies produced by suppliers instead internally, among others. de Boer et al. (2001) made a literature review of the methods which support supplier selection. According to these authors, such methodologies effectively increase the efficiency and effectiveness of the procurement processes. These methodologies take into account a greater number of criteria, in addition to the purchase price of the material, component or subassembly, allowing such decisions to be taken in terms of the long term. Supplier selection methods and tools improve the decision making process with the introduction of intangible factors such as risk. The adoption of methodologies for supplier selection, may allow 
eliminating redundant criteria and alternatives in the evaluation process, such as the use of audit programs. Finally, they give support for an easier communication of the differences between the alternatives, making decisions clearer if further explanations are necessary for internal control purposes as well as to manage the relationship with the different suppliers.

The TCO is a methodology developed to determine the total cost of ownership of a product or service provided by a particular supplier, through a complete investigation of the different cost items which composed the real cost of buying from a specific supplier. According to Ferrin and Plank (2002), the Total Cost of Ownership (TCO) is a methodology used in leading companies in worldwide supply chains. TCO aims to determine the true cost of buying a particular good or service from a particular supplier, accounting for it all costs associated with the purchasing activity (Degraeve et al., 2005), using the monetary quantification of all financial and non-financial attributes (Morssinkhof et al., 2011).

The TCO approach considers additional costs such as expenses on the implementation of an order, costs with searching activities and qualification of the supplier, transportation costs, insurance costs, warranties, product inspection and quality costs, replacement possibilities, downtime caused by failures, etc.

According to Dickson (1966), the main criteria to be considered in selecting a supplier are: quality, delivery, performance history, warranties and claims policies, supplier facilities and production capacity, price, technical capability, financial position, performance procedures, communication systems, reputation and position in the industry, degree of commitment to the business, management and organizational capacity, level of operational control, repair services capabilities, location, level of training and existence of reciprocal agreements.

Ferrin and Plank (2002) used a questionnaire to enumerate the major cost factors that affect the TCO of the companies surveyed. This questionnaire was sent to members of the Institute for Supply Management (ISM). In summary, these authors reported that the criteria for the selection of suppliers are divided into thirteen categories: operating costs, quality, customer-related costs, logistics, technological advantages, starting price, opportunity cost, capacity and reliability, maintenance, inventory costs, transaction costs, lifecycle costs, and others.

About $62 \%$ of firms surveyed by Ferrin and Plank (2002) reported that the TCO is used in less than $40 \%$ of the purchases. These results are consistent with the work of Ellram (1995) which states that the methodology is not widely publicized because its application is difficult. On the other hand, the results indicated that the main application of TCO (28.8\% of cases) is related to the purchase of capital goods, i.e. investments and equipment purchases.

Nevertheless, it is particularly important to highlight that the TCO is particularly relevant to support decision making in terms of purchasing materials and components for the production of a large quantity of products. These cases of selecting suppliers through the TCO in the manufacturing industry are less well documented and analyzed in the literature.

TCO for "continuous delivery" of materials, component or subassemblies in a supply chain is very different and much more demanding than the total cost of 
ownership of an equipment (e.g. computers, printers, etc.). In these cases, TCO is essentially a lifecycle cost computation adding to the acquisition cost of the equipment, the expected amount of operation and maintenance costs in order to compare better different alternatives. This paper is about TCO on this context, i.e. to compare supplying alternatives in a manufacturing environment of generally global supply chains.

\section{Case Study}

The research approach used in this research fits into the type 2 case study (study of several units of analysis in one case) according to Yin (1994) classification. In this research, they were studied and analyzed three cases of application of the TCO methodology which represent the three units of analysis. In a case study, it is desirable to use the largest number of sources to ensure their reliability (Yin, 1994). In this research project, the main sources of information used were: internal documentation, records and files, interviews, direct observation and participant observation of the process of supplier selection.

Thus, in this research project it was conducted an exploratory case study in order to understand and formulate hypotheses about the conditions of operation of TCO in practice. This case study took place between February and October.

The COMPANY is located in the North of Portugal and belongs to a worldwide corporation with several companies, plants around the world and thousands of workers. The plant located in Portugal produces electronic components, namely car radios, navigation systems, appliances and boilers. The various group companies are grouped into three business units: Automotive Technology, Industrial Technology and Consumer Goods. The department of Purchasing / Project Management and Preventive Planning Purchasing Quality is responsible for various projects and functions but assumes mainly the role of "interface" between suppliers and the company. This department exists in several locations of the company around the world: in Germany, southwest Asia, China and Portugal. Although this section is located inside the Portuguese plant, it is assumed as a purchases service provider and reports directly to the central purchasing department. The section has six employees who are "driven by product", that is, each collaborator is responsible for ensuring the appointment of suppliers of all components required for each particular product, as well as to track the entire process.

\section{$4 \quad$ Findings}

The company has at its disposal a wide range of suppliers around the world to guarantee the diversity and volume of components needed for it large portfolio of products. When selecting the best vendor for each project the company uses a TCO computation software in which are inserted different data about the component, potential suppliers and their prices. The result of the calculation is the TCO of the component in question, which details the purchase cost, i.e. the price of the part, price of packaging, 
the initial cost of tools and molds, shipping costs, inventory costs, costs of appointment of supplier, quality and other costs.

To be able to use the TCO method in a daily basis, the collaborators of the department of Purchasing have access to a computation program that runs on the internet browser through the firm's intranet. This case study is very interesting, even paradigmatic, because the TCO computation model is a decision tool developed internally in the company and there are not other examples of such kind of programs documented in the literature. This model considers several and different inputs for the computation of the TCO. Attending confidentiality considerations the calculation equations and algorithms cannot be explained in detail.

The TCO tool developed in this company requires inputs of four different levels: global (at the parent company), at the business unit level (does not contain numeric values); at the level of the plant (factory); at the project level. The inputs necessary and the outputs produced by the model are summarized in eight categories as it is shown in Figure 1. After the introduction of the inputs, a sheet with detailed results for each of the first three years of the project and the overall results of the TCO by supplier is presented.

Table 1. TCO tool: inputs and outputs

\begin{tabular}{ll}
\hline \multicolumn{1}{c}{ Inputs } & \multicolumn{1}{c}{ Outputs } \\
\hline Projetc details & Preço \\
Information about the supplier & Tool costs \\
Order costs & Packaging costs \\
Transportation costs & Transportation costs \\
Inventory costs & Inventory costs \\
Appointment costs & Appointment costs \\
Quality costs & Quality costs \\
Other costs & Other costs \\
\hline
\end{tabular}

For the overall results of the TCO it is still possible to obtain graphs where it is shown visually the weight of the different components in the final cost structure for each potential supplier. To help collaborators in the introduction of the data, there is an internal document developed by the logistics department of the company. In this document, we can found typical values for transportation costs, shipping conditions, type of inspection procedures, etc. This document contains confidential information for the company, so its contents cannot be disclosed.

However, it is important to note that, in a few cases, the selection of a supplier may consider additional aspects beyond the TCO. In some cases, the final decision may exclude suppliers with lower TCO due to various reasons such as: 1) purchasing strategies that define what is not desirable to carry out business with the supplier in question, 2) the financial rating of suppliers, which may put into question the economic viability of such alternative, 3) allocation limits defined by the business unit (e.g. a supplier cannot have more than $30 \%$ of the turnover dependent on a the business unit, or if more than $50 \%$ of suppliers sales are with companies in the group). 
The TCO tool was analyzed and discussed through 3 different situations. The three cases analyzed are quite different but the results are comparable. TCO is about the consideration of indirect costs to select the best supplier. Nevertheless, direct costs remain important, i.e., the purchase price, the price of packing, tool costs, among others, have a significant contribution to the final TCO. In Case 1, the three suppliers were Portuguese firms and competed within very similar conditions, which led to the "price of parts" to be the main factor which explain the differences between suppliers. In Case 2 were surveyed four suppliers, one from Malaysia and three Portuguese. For the Portuguese suppliers the main cost drivers were the part price and the costs with the tooling, the remaining parameters originated residual values. On the other hand, the TCO of the Malaysian supplier was quite incremented by the value of shipping costs. In Case 3, two suppliers were Portuguese, one German and the last one Chinese. The results obtained through the TCO application indicated that the part price and the cost of the tool were the factors most important, despite the value of inventory and shipping costs are also considerable for the German and the Chinese suppliers. The weight of each of the cost drivers on the final TCO, in these three situations, is presented in Table 2.

Table 2. Cost items proportion on total cost

\begin{tabular}{lcccc}
\hline Cost itens & Case 1 & Case 2 & Case 3 & Average \\
\hline Acquisition costs & 50.2 & 44.1 & 72.3 & 55.5 \\
Package costs & 0 & 0 & 0 & 0 \\
Tool costs & 43.4 & 54.1 & 14.5 & 37.4 \\
Transport costs & 1.5 & 0.1 & 5.7 & 2.4 \\
Inventory costs & 3.0 & 1.0 & 5.7 & 3.3 \\
Nomination costs & 0 & 0 & 0 & 0 \\
Quality costs & 1.8 & 0.6 & 1.7 & 1.4 \\
Other costs & 0 & 0 & 0 & 0 \\
Total & 100 & 100 & 100 & 100 \\
\hline
\end{tabular}

In the three situations presented, TCO value is 1,2 to 3,1 times the purchase price of the piece and this fact demonstrates the need for a rigorous analysis of the remaining costs in the selection of suppliers. If only the selected suppliers are considered, the value of the TCO represents a lower variability: between 1.3 to 2.3 times the value of the purchase price of the part. Indeed, the complete cost of a part or component, i.e. its TCO, is much more than the immediate and direct purchase price.

It is interesting to note that in each situation studied, the supplier with the lowest TCO was always the one that showed a lower purchase cost, which does not mean that the application of the TCO methodology is unnecessary in these cases. Indeed, the realization of the TCO calculation allowed identifying costs that deserved special attention for the negotiations with the different suppliers.

For example, in Case 2, the computation of the TCO identified cost drivers that have received particular attention in the second round of negotiations, clarifying the selection of the best supplier. In Case 3, on the other hand, the application of the TCO 
permitted to highlight and understand the differences in between suppliers which presented direct costs of the part very similar.

\section{Conclusions}

The costs with the acquisition of materials and components constitute a major expenditure in many firms and a significant portion of production costs in various industries. The costs that reflect the purchasing function represent between $50 \%$ and $90 \%$ of the production cost (Weber et al., 2010, de Boer et al., 2001; Ellram and Siferd, 1998). On the other hand, the increasing complexity of products and services, the reduction of product life cycles, increased complexity of the processes in companies, the greater interconnection between customers and suppliers and other aspects make the success of a company to be very dependent of its suppliers and the relationship that they have among them (e.g. Micheli et al., 2009).

In this context, the purchasing function can contribute for higher levels of production efficiency and the competiveness of the firm, reducing business costs and therefore increasing company's profit (Dowlatshahi, 2000).

This paper illustrates the application of TCO for continuous supply, in a company that uses this methodology in a systematic and structured approach. The literature does not offer real examples of TCO in practice; thus, findings of this research project represent a contribution to the literature.

\section{References}

1. Aissaoui, N., Haouari, M., Hassini, E.: Supplier selection and order lot sizing modeling: a review. Computers \& Operations Research 34, 3516-3540 (2007)

2. Bevilacqua, M., Ciarapica, F., Giacchetta, G.: A fuzzy-QFD approach to supplier selection. Journal of Purchasing \& Supply Management 12, 14-27 (2006)

3. Che, Z., Wang, H.: Supplier selection and supply quantity allocation of common and noncommon parts with multiple criteria under multiple products. Computers \& Industrial Engineering 55, 110-133 (2008)

4. de Boer, L., Labro, E., Morlacchi, P.: A review of methods supporting supplier selection. European Journal of Purchasing \& Supply Management 7, 75-89 (2001)

5. Degraeve, Z., Roodhooft, F., Van Doveren, B.: The use of total cost of ownership for strategic procurement: a company-wide management information system. Journal of the Operational Research Society, 51-59 (2005)

6. Dickson, G.W.: An analysis of vendor selection systems and decisions (1966)

7. Dogan, I., Aydin, N.: Combining Bayesian Networks and Total Cost of Ownership method for supplier selection analysis. Computers \& Industrial Engineering (2011)

8. Dowlatshahi, S.: Designer-buyer-supplier interface: Theory versus practice. International Journal of Production Economics 63, 111-130 (2000)

9. Dyer, J.: Specialized Supplier Networks as a Source of Competitive Advantage: Evidence from the Auto Industry. Strategic Management Journal 17, 271-291 (1996)

10. Ellram, L., Siferd, S.: Total Cost of Ownership: A Key Concept In Strategic Cost Management Decisions. Journal of Business Logistics, 55-84 (1998) 
11. Ellram, L.: Total cost of ownership: An analysis approach for purchasing. Arizona State University, Tempe (1995)

12. Ferrin, B., Plank, R.: Total cost of Ownership Models: An Exploratory Study. Journal of Supply Chain Management (2002)

13. Ho, W., Xu, X., Dey, P.: Multi-criteria decision making approaches for supplier evaluation and selection: A literature review. European Journal of Operational Research 202, 16-24 (2010)

14. Humphreys, P., Wong, Y., Chan, F.: Integrating environmental criteria into the supplier selection process. Journal of Materials Processing Technology 138(1-3), 349-356 (2003)

15. Micheli, G., Cagno, E., Giulio, A.D.: Reducing the total cost of supply through riskefficiency-based supplier. Journal of Purchasing \& Supply Management 15, 166-177 (2009)

16. Morssinkhof, S., Wouters, M., Warlop, L.: Effects of providing total cost of ownership information on attribute weights in purchasing decisions. Journal of Purchasing \& Supply Management (2011)

17. Seal, W., et al.: Enacting a European supply chain: a case study on the role of management accounting. Management Accounting Research 10, 303-322 (1999)

18. Snijders, C., Tazelaar, F., Batenburg, R.: Electronic decision support for procurement management: evidence on whether computers can make better procurement decisions. Journal of Purchasing \& Supply Management 9, 191-198 (2003)

19. Weber, M., Hiete, M., Lauer, L., Rentz, O.: Low cost country sourcing and its effects on the total cost of ownership structure for a medical devices manufacturer. Journal of Purchasing \& Supply Management 16, 4-16 (2010)

20. Yin, R.K.: Case study research: Design and methods. Applied Social Research Methods Series, vol. 5. SAGE Publications (1994) 